The Astrophysical Journal, 220:L15-L19, 1978 February 15

(c) 1978. The American Astronomical Society. All rights reserved. Printed in U.S.A.

\title{
BARIUM AND NEODYMIUM ISOTOPIC ANOMALIES IN THE ALLENDE METEORITE
}

\author{
M. T. McCulloch and G. J. Wasserburg \\ The Lunatic Asylum, Division of Geological and Planetary Sciences, ${ }^{*}$ Caltech, Pasadena, CA 91125 \\ Received 1977 October 14; accepted 1977 November 10
}

\begin{abstract}
Isotopic anomalies have been found for $\mathrm{Ba}$ and $\mathrm{Nd}$ in two inclusions from the Allende meteorite. These inclusions are typical $\mathrm{Ca}-\mathrm{Al}$-rich objects associated with early condensates from the solar nebula but have distinctive $\mathrm{O}$ and $\mathrm{Mg}$ isotopic anomalies of the FUN type. Sample C1 shows a depletion only in ${ }^{135} \mathrm{Ba}$ of 2 parts in $10^{4}$ and normal Nd. Sample EK1-4-1 shows large positive excesses in the unshielded isotopes ${ }^{135} \mathrm{Ba}$ and ${ }^{137} \mathrm{Ba}$ of 13.4 and 12.3 parts in $10^{4}$, respectively. The $\mathrm{Nd}$ isotopic composition in EK1-4-1 is highly aberrant in at least five isotopes. Both the $\mathrm{Ba}$ and $\mathrm{Nd}$ anomalies can be explained by a model of $r$-process addition. These anomalies are found to be uniform between coexisting mineral phases. These observations show the existence of substantial isotopic anomalies in refractory elements in the neighborhood of $\mathrm{Xe}$ and extend the range of elements showing isotopic effects to $\mathrm{O}, \mathrm{Ne}, \mathrm{Mg}, \mathrm{Ca}, \mathrm{Kr}, \mathrm{Xe}, \mathrm{Ba}$, and $\mathrm{Nd}$. The observations, in conjunction with the presence of ${ }^{26} \mathrm{Al}\left(\tau_{1 / 2}=7 \times 10^{5}\right.$ years $)$, are interpreted as the result of a nearby supernova explosion which produced elements over a wide mass range and injected them into the early solar nebula shortly before condensation.
\end{abstract}

Subject headings: meteors and meteorites - nucleosynthesis - stars: supernovae

\section{INTRODUCTION}

$\mathrm{Ba}$ and $\mathrm{Nd}$ isotopic anomalies have been discovered in one inclusion in the Allende meteorite and $\mathrm{Ba}$ isotopic anomalies in a second inclusion from the same meteorite. Anomalies in $\mathrm{Ca}$ from the same inclusions are reported in a companion Letter by Lee, Papanastassiou, and Wasserburg (1978). A new search for isotopic variations in $\mathrm{Ba}$ was undertaken because of the existence of isotopic anomalies in $\mathrm{O}$ and $\mathrm{Mg}$ in Allende inclusions. $\mathrm{Ba}$ has seven stable isotopes which are believed to have been made in the $p$-, $s$-, and $r$-processes (Burbidge et al. 1957, hereafter $\mathrm{B}^{2} \mathrm{FH}$ ). The relative contributions to each of the isotopes by these processes are quite different. The existence of isotopic anomalies in meteoritic, terrestrial, and solar Xe which are not attributable to the radioactive decay of known nuclides also suggested that nuclear effects might be present in the neighborhood of atomic number $Z=56$. Previous studies of $\mathrm{Ba}$ using high-precision methods were reported by Eugster, Tera, and Wasserburg (1969, hereafter ETW), who found no evidence for nonlinear isotopic shifts to a level of $10^{-4}$ and a maximum mass fractionation of $2 \times 10^{-4}$ per mass unit. Measurements of ${ }^{142} \mathrm{Nd} /{ }^{144} \mathrm{Nd}$ from an inclusion from Allende have been published by Scheinin, Lugmair, and Marti (1976). These workers have tentatively inferred small excesses in ${ }^{142} \mathrm{Nd}$ which they have attributed to decay of extinct ${ }^{146} \mathrm{Sm}$. However, the inherent precision of the data was not sufficient to clearly resolve this effect.

Inclusions in which $\mathrm{Ba}$ and $\mathrm{Nd}$ isotopic effects were found are $\mathrm{Ca}-\mathrm{Al}$-rich objects typical of the type considered as high-temperature condensation products in the solar nebula (see Grossman 1972). They contain

* Division Contribution No. 2979 (252). coarse-grained fassaitic pyroxene, melilite, spinel, and plagioclase. They also contain fine-grained alteration products associated with melilite and plagioclase which are rich in a "sodalite"-like material and believed to result from a late-stage reaction of early condensates with cooler, volatile-rich material in the solar nebula which altered the oxygen isotopic composition of the melilite (Clayton and Mayeda 1977; Wasserburg, Lee, and Papanastassiou 1977, hereafter WLP). These inclusions are known to be distinctive, as they contain magnesium with negative values of $\delta^{26} \mathrm{Mg}$ and oxygen which does not lie on the usual correlation line between "normal" oxygen $\left(\mathrm{O}_{\mathrm{N}}\right)$ and extraordinary oxygen $\left(\mathrm{O}_{\mathrm{E}}\right)$ consisting of nearly pure ${ }^{16} \mathrm{O}$ (Clayton, Grossman, and Mayeda 1973). The $\mathrm{Mg}$ in these inclusions shows ${ }^{26} \mathrm{Mg} /{ }^{24} \mathrm{Mg}$ ratios shifted from normal values by $2 \%$ and $3 \%$ per mass unit, favoring the heavier isotopes. These large shifts are almost quantitatively what would be expected by mass fractionation (F) with small but distinct residual negative anomalies in ${ }^{26} \mathrm{Mg}$ which are attributed to unknown nuclear processes (UN). This class of anomalies was designated as FUN anomalies (WLP).

\section{RESULTS}

Procedures were similar to those described by ETW. Data were taken on the Lunatic I and III mass spectrometers (Wasserburg et al. 1969) which give the same self-consistent $\mathrm{Ba}$ isotopic ratios within 3 parts in $10^{5}$. An improvement in sensitivity by a factor of 50 and in precision by a factor of 2 was achieved over ETW. Typical ion beams for ${ }^{138} \mathrm{Ba}$ were $2 \times 10^{-11} \mathrm{~A}$ when collecting data on masses 134-138. Data for the rare isotopes $130-132$ were taken with the ${ }^{138} \mathrm{Ba}$ ion beam at $10^{-10} \mathrm{~A}$. Data are given in Table 1 for isotope $k$ as 
TABLE 1

BARIUM ISOTOPIC VARIATIONS*

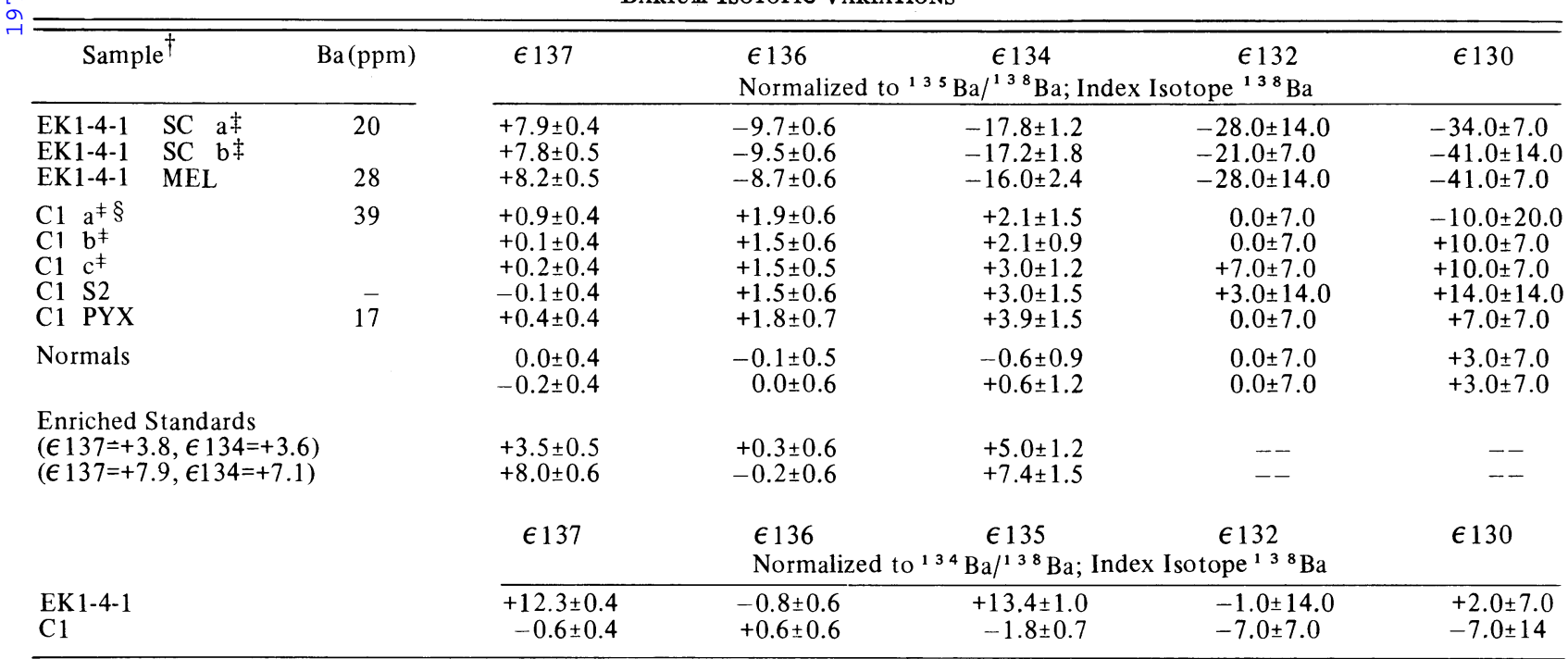

*Errors are $2 \sigma_{\text {mean }}$. Deviations in parts per ten thousand relative to our grand mean of terrestrial normals: ${ }^{137} \mathrm{Ba} /{ }^{138} \mathrm{Ba}=0.156515 \pm 4$; ${ }^{136} \mathrm{Ba} /{ }^{1{ }^{3} 8} \mathrm{Ba}=0.109540 \pm 4 ;{ }^{134} \mathrm{Ba} /{ }^{138} \mathrm{Ba}=0.033710 \pm 4 ;{ }^{132} \mathrm{Ba} /{ }^{138} \mathrm{Ba}=0.001412 \pm 1 ;{ }^{130} \mathrm{Ba} /{ }^{138} \mathrm{Ba}=0.001476 \pm 1 ;{ }^{135} \mathrm{Ba} /{ }^{138} \mathrm{Ba}=$ 0.091940. †PYX = pyroxene; $\mathrm{MEL}=$ melilite; $\mathrm{S} 2, \mathrm{SC}=$ splits of crushed inclusion. $\quad$ ‡Repeat analysis of solution. $\S_{\text {Analyzed on }}$ L III mass spectrometer.

deviations from the normal ratios in parts in $10^{4}$ with ${ }^{138} \mathrm{Ba}$ as the index isotope:

$$
\epsilon k=\left(R_{k / 138} \mathrm{C} / R_{k / 138} \mathrm{~N}-1\right) \times 10^{4}
$$

where $R_{k / 138^{\mathrm{N}}}=\left({ }^{k} \mathrm{Ba} /{ }^{138} \mathrm{Ba}\right)_{\text {normal }}$ and $R_{k / 138}{ }^{\mathrm{C}}=\left({ }^{k} \mathrm{Ba} /\right.$ ${ }^{138} \mathrm{Ba}$ ) measured in the sample and normalized for mass fractionation assuming ${ }^{135} \mathrm{Ba} /{ }^{138} \mathrm{Ba}$ to equal the terrestrial value. Standards enriched in ${ }^{137} \mathrm{Ba}$ and ${ }^{134} \mathrm{Ba}$ were measured to establish the sensitivity to which nonlinear anomalies could be detected (see Table 1).

Samples from Allende, including $\mathrm{Ca}-\mathrm{Al}$-rich chondrules and aggregates, olivine chondrules, a pyroxene chondrule, and total meteorite, were analyzed for $\mathrm{Ba}$. With the exception of the FUN samples, C1 and EK1-4-1, all other samples yield a $\mathrm{Ba}$ isotopic composition identical to terrestrial $\mathrm{Ba}$ within limits of error (see Fig. 1). A preliminary report on these data, excluding C1 and EK1-4-1, was published by McCulloch, Papanastassiou, and Wasserburg (1976). A small sample $\left(2 \times 10^{-8} \mathrm{~g}\right)$ of $\mathrm{Ba}$ from high-purity anorthite from WA, which shows a $10 \%$ excess of ${ }^{26} \mathrm{Mg}$, and a large sample from the associated pyroxene, were analyzed and found to be normal. The first analysis

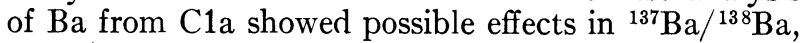
${ }^{136} \mathrm{Ba} /{ }^{138} \mathrm{Ba}$, and ${ }^{134} \mathrm{Ba} /{ }^{138} \mathrm{Ba}$. An aliquot of the solution was again separated and analyzed, and the anomalies in ${ }^{136} \mathrm{Ba} /{ }^{138} \mathrm{Ba}$ and ${ }^{134} \mathrm{Ba} /{ }^{138} \mathrm{Ba}$ were reproduced. The smaller anomaly in ${ }^{137} \mathrm{Ba} /{ }^{138} \mathrm{Ba}$ was not reproduced. A second split of the bulk inclusion (C1-S2) and a sample of pyroxene from $\mathrm{C} 1$ were analyzed and yielded the same shifts in ${ }^{136} \mathrm{Ba} /{ }^{138} \mathrm{Ba}$ and ${ }^{134} \mathrm{Ba} /{ }^{138} \mathrm{Ba}$. The nonlinear anomalies, while small, are reproducible by using different spectrometers and different samples.
The only discrepancy is the measurement of ${ }^{137} \mathrm{Ba} /$ ${ }^{138} \mathrm{Ba}$ for C1a. A sample of EK1-4-1 SC, consisting dominantly of pyroxene, was analyzed and yielded extremely large deviations which exceed the $2 \sigma_{\text {mean }}$ errors by over a factor of 10 . A second mass spectrometer run was performed and isotopic ratios were determined over a wide range in filament temperature. Data were taken for masses 134-138 with the ion beam ranging from 0.5 to $2 \times 10^{-11} \mathrm{~A}$ to test for changes in the ratios. The values for those isotopic ratios that could be measured at these emission levels were all identical within error to the means for the high-intensity data of both SC samples. Data for masses 130-135 were taken with the ion beam at $8 \times 10^{-11} \mathrm{~A}$ and were also identical with those obtained in the previous run. In addition, a melilite separate from EK1-4-1 was analyzed and yielded an isotopic composition identical to that found for the SC sample. These data demonstrate large nonlinear isotopic anomalies in EK1-4-1 which are the same for different phases with $\mathrm{Ba}$ concentrations differing by $40 \%$. For all runs the spectrum was scanned at high sensitivity between masses 120 and 160 and no interfering masses were identified. The only peaks seen were due to $\mathrm{LaO}$ and $\mathrm{CeO}$, which were present at a level of $2 \times 10^{-12} \mathrm{~A}$ or less and do not interfere with $\mathrm{Ba}$. During data collection the ratios $\mathrm{Ba}^{+} / \mathrm{LaO}^{+}$and $\mathrm{Ba}^{+} /$ $\mathrm{CeO}^{+}$changed by over a factor of 2 without any changes in the $\mathrm{Ba}$ ratios.

Upon finding effects in $\mathrm{Ba}$, we deemed it necessary to establish whether anomalies existed in other higher$Z$ elements, and a study of $\mathrm{Nd}$ was made. The procedures for Nd are similar to those described by DePaolo and Wasserburg (1976). Nd data are presented in 
Table 2 as deviations (see eq. [1]) from standard normal ratios, with ${ }^{144} \mathrm{Nd}$ as the index isotope and mass fractionation corrections applied by using ${ }^{150} \mathrm{Nd} /{ }^{142} \mathrm{Nd}$. Sample C1-S2 has a Nd isotopic composition indistinguishable from terrestrial normal. However, sample EK1-4-1 SC has large deviations of $\mathrm{Nd}$ isotopic composition from normal which exceed the errors by over a factor of 30. Data were collected for all isotopes with the ${ }^{144} \mathrm{NdO}^{+}$beam ranging from 1 to $6 \times 10^{-11} \mathrm{~A}$, and isotopic ratios remained constant within experimental errors. The melilite separate from EK1-4-1 was analyzed for $\mathrm{Nd}$ and gave an isotopic composition identical to that of SC, except for mass 143 , which is affected by ${ }^{147} \mathrm{Sm}$ decay. The $\mathrm{Nd}$ concentration in the melilite is lower than that in SC by a factor of 2.4. For the samples $\mathrm{C} 1$ and EK1-4-1 the mass fractionation correction applied to both $\mathrm{Ba}$ and $\mathrm{Nd}$ was less than $\sim 3 \%$ per mass unit and within the same range as applied to the terrestrial normal.

\section{DISCUSSION}

Most samples of the Allende meteorite contain $\mathrm{Ba}$ of normal isotopic composition. Some of the samples analyzed for $\mathrm{Ba}$ had substantial contributions of $\mathrm{O}_{\mathrm{E}}$ (up to $3 \%$ ) and of excess ${ }^{26} \mathrm{Mg}$ (up to $10 \%$ ) correlated with ${ }^{27} \mathrm{Al}$. It follows that no obvious correlation exists between these nuclear effects at low $Z$ and $\mathrm{Ba}$. In contrast, the two inclusions which are distinguished by having FUN anomalies also show distinct nonlinear isotopic anomalies in $\mathrm{Ba}$. Inclusion $\mathrm{C} 1$ has anomalies at

\section{BARIUM ISOTOPIC COMPOSITION \\ NORMALIZED TO $135 / 138=0.09194$}

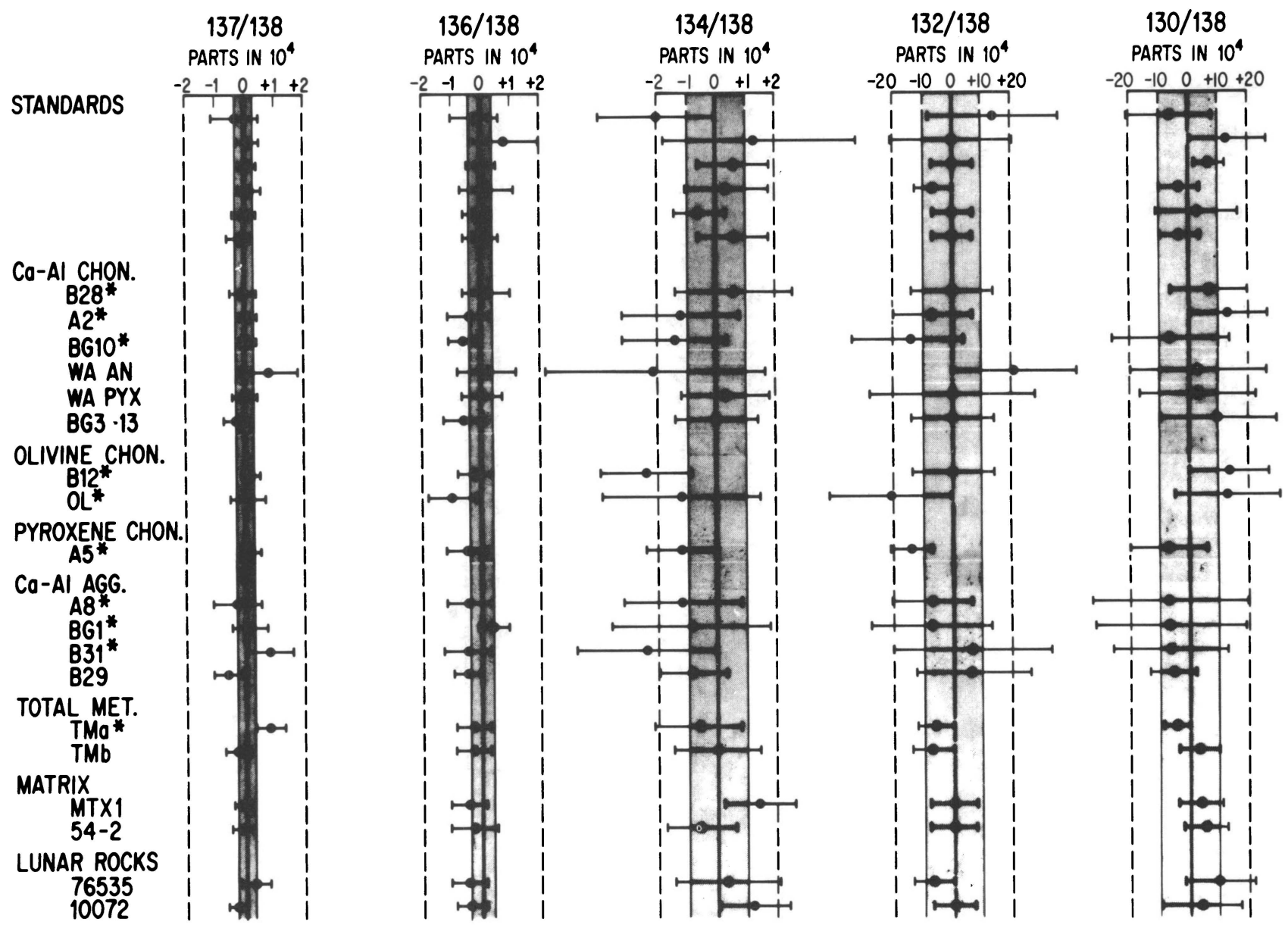

* MEASURED ON LIII

FIG. 1.-Bar graph showing fractional deviations in the isotopic composition of Ba relative to normal for all Allende samples and two lunar samples studied in this work excluding FUN samples C1 and EK1-4-1. Reference line at 0 is mean of terrestrial values. 
TABLE 2

NEODYMIUM IsOTOPIC VARIATIONS*

\begin{tabular}{|c|c|c|c|c|c|c|c|c|c|}
\hline \multicolumn{2}{|l|}{ Sample } & $\mathrm{Nd}(\mathrm{ppm})$ & Sm $(\mathrm{ppm})$ & $\epsilon 142$ & $\epsilon 143^{\dagger}$ & $\epsilon 145$ & $\epsilon 146$ & $\epsilon 148$ & $\epsilon 150$ \\
\hline & & & & \multicolumn{6}{|c|}{ Normalized to ${ }^{150} \mathrm{Nd} / /^{142} \mathrm{Nd}$; Index Isotope ${ }^{144} \mathrm{Nd}$} \\
\hline $\begin{array}{l}\text { EK1-4-1 } \\
\text { EK 1-4-1 } \\
\text { EK 1-4-1 }\end{array}$ & $\begin{array}{l}\text { SC a } \\
\text { SC b } \\
\text { MEL }\end{array}$ & $\begin{array}{r}11.7 \\
11.7 \\
4.9\end{array}$ & $\begin{array}{l}4.1 \\
4.1 \\
1.4\end{array}$ & $\begin{array}{l}-9.6 \pm 0.3 \\
-9.9 \pm 0.3 \\
-9.2 \pm 0.4\end{array}$ & $\begin{array}{r}+24.1 \pm 0.4 \\
+23.5 \pm 0.4 \\
-0.1 \pm 0.7\end{array}$ & $\begin{array}{l}+2.7 \pm 0.6 \\
+2.4 \pm 0.4 \\
+2.3 \pm 0.9\end{array}$ & $\begin{array}{l}-12.4 \pm 0.4 \\
-12.5 \pm 0.4 \\
-12.9 \pm 0.5\end{array}$ & $\begin{array}{l}-1.5 \pm 0.5 \\
-1.5 \pm 0.9 \\
-0.5 \pm 1.0\end{array}$ & $\begin{array}{l}-9.6 \pm 0.3 \\
-9.9 \pm 0.3 \\
-9.2 \pm 0.4\end{array}$ \\
\hline \multirow{2}{*}{\multicolumn{2}{|c|}{$\mathrm{C} 1 \mathrm{~S} 2$}} & -- & -- & $+0.1 \pm 0.3$ & $+0.5 \pm 0.4$ & $+0.3 \pm 0.6$ & $-0.1 \pm 0.5$ & $+1.1 \pm 0.9$ & $+0.1 \pm 0.3$ \\
\hline & & & & \multicolumn{6}{|c|}{ Normalized to ${ }^{144} \mathrm{Nd} /{ }^{142} \mathrm{Nd}$; Index Isotope ${ }^{142} \mathrm{Nd}$} \\
\hline $\begin{array}{l}\text { EK 1-4-1 } \\
\text { For } f^{*}=2\end{array}$ & & & & & $\begin{array}{l}+28.9 \pm 0.4 \\
+38.9 \pm 0.4\end{array}$ & $\begin{array}{r}-2.1 \pm 0.6 \\
+27.9 \pm 0.6 \\
\end{array}$ & $\begin{array}{l}-22.0 \pm 0.6 \\
+18.0 \pm 0.6\end{array}$ & $\begin{array}{r}-20.7 \pm 0.9 \\
+39.3 \pm 0.9\end{array}$ & $\begin{array}{l}-38.4 \pm 1.0 \\
+41.6 \pm 1.0\end{array}$ \\
\hline
\end{tabular}

*Deviations relative to the grand mean of terrestrial normals: ${ }^{142} \mathrm{Nd} /{ }^{144} \mathrm{Nd}=1.138266 \pm 9 ;{ }^{145} \mathrm{Nd} /{ }^{144} \mathrm{Nd}=0.348968 \pm 6$; ${ }^{146} \mathrm{Nd} / /^{14} \mathrm{Nd}=0.724109 \pm 10 ;{ }^{148} \mathrm{Nd} /{ }^{144} \mathrm{Nd}=0.243079 \pm 6 ;{ }^{150} \mathrm{Nd} /{ }^{144} \mathrm{Nd}=0.238581$. Standard value of ${ }^{143} \mathrm{Nd} / /^{144} \mathrm{Nd}=$ 0.511836 today for chondritic Sm/Nd. G. Lugmair personal communication. † $€ 143$ variations are also due to decay of ${ }^{147} \mathrm{Sm}$ $\left(\tau_{1 / 2}=1.06 \times 10^{11}\right.$ years $) . \quad \ddagger^{*}=\left({ }^{144} \mathrm{Nd}^{*} /{ }^{144} \mathrm{Nd}\right) \times 10^{4}$.

masses 134 and 136, while inclusion EK1-4-1 shows large marked negative anomalies at 130,132, 134, and 136 , and a positive anomaly at 137 . Using normalization to a standard ${ }^{150} \mathrm{Nd} /{ }^{142} \mathrm{Nd}$ value and ${ }^{144} \mathrm{Nd}$ as the index isotope, we found inclusion $\mathrm{C} 1$ to contain normal $\mathrm{Nd}$, while inclusion EK1-4-1 shows marked negative anomalies in $\mathrm{Nd}$ at $142,146,148$, and 150 , and a positive anomaly at 145 . These observations demonstrate that isotopic anomalies exist in $\mathrm{Ba}$ and $\mathrm{Nd}$ for several isotopes in some solar-system materials. These isotopic shifts are due to nuclear effects and cannot be attributed to mass fractionation. Normalizations to ${ }^{135} \mathrm{Ba} /{ }^{138} \mathrm{Ba}$ and ${ }^{150} \mathrm{Nd} /{ }^{142} \mathrm{Nd}$ were chosen to minimize the propagation of experimental errors and are otherwise arbitrary. The isotopic shifts depend upon the two isotopes $(i, j)$ used for normalization, and the index isotope $(m)$. Generally, the deviation in parts in $10^{4}$ of isotope $k$ is given by $\epsilon_{i j}{ }^{k m}$. The fractionation per mass unit $\alpha$ is determined from $\alpha_{i j}=\left(R_{i j}{ }^{M} / R_{i j}{ }^{0}-1\right) /(i-j)$ where $M=$ measured and $0=$ standard. For small shifts, the transformation for $\epsilon$ to a new index isotope $p$ and a new normalization $(u, v)$ is given by

$\epsilon_{u v}{ }^{k p}=\epsilon_{i j}{ }^{k m}-\epsilon_{i j}{ }^{p m}+\left(\epsilon_{i j}{ }^{v m}-\epsilon_{i j}{ }^{u m} \frac{(k-p)}{(u-v)}\right.$,

As the cause of the nonlinear anomalies is obscure, it is more useful to choose a normalization which minimizes the number of isotopes at which anomalies occur. If we normalize to ${ }^{134} \mathrm{Ba} /{ }^{138} \mathrm{Ba}$ to correct for fractionation, we obtain the results shown in the bottom of Table 1 . For sample $\mathrm{C} 1$, the only variation outside of error is a deficiency at mass 135 . For EK 1-4-1, the anomalies are positive and lie at masses 137 and 135. This choice of normalization appears to minimize the number of anomalies for both samples and implies an excess in ${ }^{135} \mathrm{Ba}$ and ${ }^{137} \mathrm{Ba}$ in one sample and a deficiency in ${ }^{135} \mathrm{Ba}$ in the other. If we interpret the shifts in EK1-4-1 as due to the addition of ${ }^{135} \mathrm{Ba}$ and ${ }^{137} \mathrm{Ba}$, this requires that the exotic $\mathrm{Ba}$ excesses $(*)$ have ${ }^{137} \mathrm{Ba}^{*} /{ }^{135} \mathrm{Ba}^{*}=$ 1.6. We note that ${ }^{135} \mathrm{Ba},{ }^{137} \mathrm{Ba}$, and ${ }^{138} \mathrm{Ba}$ are unshielded and may be produced in an $r$-process. From the estimates of Seeger, Fowler, and Clayton $(1965),\left({ }^{137} \mathrm{Ba} /\right.$ $\left.{ }^{135} \mathrm{Ba}\right)_{r} \sim 1.2$, which is comparable to the calculated value. However, this value may be subject to substantial changes, using new values for the Ba cross sections (Stroud 1972) together with a detailed calculation of the branching network (Ward, Newman, and Clayton 1976). If the same number of exotic $r$-process nuclei are added to ${ }^{138} \mathrm{Ba}$ as are added at ${ }^{137} \mathrm{Ba}$, this would cause a fractional increase in the ${ }^{138} \mathrm{Ba}$ abundance by 1.00018 . This would propagate an error in the discrimination calculation of $\epsilon \sim+1.8$ at mass 130 , which is well within errors, and a deficiency of $\epsilon \sim-0.9$ at mass 136 , which is just within limits of error. No evidence has been found for variation in the abundance of the $p$ process isotopes. It does not appear possible to attribute the deficiency at 135 in $\mathrm{C} 1$ to the absence of exotic $r$-process material of the same composition inferred for EK1-4-1 owing to the lack of an effect at 137, although this may be obscured by the errors. Alternatively, the ${ }^{135} \mathrm{Ba}$ deficiency could result from a deficiency in $r$ process relative to $s$-process contributions, with $r$-process production ratios shifted from ${ }^{137} \mathrm{Ba}^{*} /{ }^{135} \mathrm{Ba}^{*} \sim 1.6$. A deficiency in ${ }^{135} \mathrm{Ba}$ could occur if there were a late-stage addition of $r$-process nuclei and if $\mathrm{Ba}$ were condensed before ${ }^{135} \mathrm{Cs}\left(\tau_{1 / 2}=2.3 \times 10^{6} \mathrm{yr}\right)$ decayed. The deficiency in $\mathrm{C} 1$ is particularly important, as it implies that the average solar-system value must be made up by an addition of at least 2 parts in $10^{4}$ of exotic ${ }^{135} \mathrm{Ba}$. The anomalies in EK1-4-1 are not compatible with in situ fission subsequent to crystallization, as the shifts in $\mathrm{Ba}$ and $\mathrm{Nd}$ are the same for the total sample and the melilite, although $\mathrm{Ba} / \mathrm{Nd}$ differ by a factor of 3 . Further, the fission hypothesis is not in consonance with the large number of other isotopic anomalies for many elements ranging to low $Z$.

To expose whether the Nd effects are due to addition of $r$-process nuclei, ${ }^{142} \mathrm{Nd}$ (shielded) and ${ }^{144} \mathrm{Nd}$, which must have a large $s$-process component, are used for normalization. However, the resultant pattern of deviations does not generate positive anomalies for all other isotopes (Table 2). To obtain all positive values, a substantial addition to ${ }^{144} \mathrm{Nd}$ must be assumed $\left(f^{*}=\right.$ 20 parts in $10^{4}$ ). To demonstrate general excesses compatible with $r$-process addition, it will be necessary 
to obtain data on Sm and other refractory elements in this mass region with two shielded isotopes.

From the data reported here, as well as the wide range of $\mathrm{Xe}$ isotopic anomalies, it is reasonable to consider that ${ }^{129} \mathrm{I}$ may also have been added in the same process. Assuming that the negative $\mathrm{Ba}$ anomaly in $\mathrm{C} 1$ was representative of a deficiency in the whole solar nebula prior to the addition of material as found in EK1-4-1, then as $\left({ }^{135} \mathrm{Ba} /{ }^{127} \mathrm{I}\right)_{\odot} \sim 0.3$ (Cameron 1973), we obtain ${ }^{135} \mathrm{Ba}^{*} /{ }^{127} \mathrm{I} \sim 0.5 \times 10^{-4}$. The time scale for production and injection of exotic low- $Z$ elements is $\sim 3 \times 10^{6}$ years from the interpretation by Lee, Papanastassiou, and Wasserburg (1977, hereafter LPW) regarding the in situ decay of ${ }^{26} \mathrm{Al}$ in the solar nebula. If this time scale also applies to the injected exotic high- $Z$ elements, then any associated ${ }^{12}{ }^{2} \mathrm{I}\left(\tau_{1 / 2}=1.6 \times\right.$ $10^{7}$ years) will not have decayed. Thus, if ${ }^{129} \mathrm{I}$ were added along with the exotic nuclei identified here and commensurate in amount with the small Ba deficiency, this could account for the observed ratio of ${ }^{129} \mathrm{I} /{ }^{127} \mathrm{I} \sim$ $10^{-4}$. Such a model of small last-"minute" injection of $r$-process material is fully compatible with the Xe observations by Reynolds and his co-workers (Reynolds 1960; Podosek 1970). This implies that the observed ${ }^{129} \mathrm{Xe}$ effects are not from ${ }^{129} \mathrm{I}$ produced by earlier galactic nucleosynthesis and that the ${ }^{129} \mathrm{I}-{ }^{244} \mathrm{Pu}$ time scale of $\sim 1-2 \times 10^{8}$ years is an accident due to the injection of newly made exotic ${ }^{129} \mathrm{I}$ in a ratio of ${ }^{12}{ }^{12} \mathrm{I} /$ ${ }^{127} \mathrm{I} \sim 10^{-4}$ (see Schramm and Wasserburg 1970).

Isotopic anomalies have been known for $\mathrm{Ne}, \mathrm{Kr}$, and $\mathrm{Xe}$ for over 15 years. It now appears that isotopic anomalies are present in solar-system material for $\mathrm{O}$, $\mathrm{Ne}, \mathrm{Mg}, \mathrm{Ca}, \mathrm{Kr}, \mathrm{Xe}, \mathrm{Ba}$, and $\mathrm{Nd}$. This must be due to incomplete mixing of dust and gas from different sources at the time of formation of early condensates. From the data described here and in the companion Letter, it is manifest that the anomalies may extend to much higher atomic number. This may well extend through the transuranics, which could alter the calculation of the time between the termination of nucleosynthesis and the formation of the solar system and could further contribute anomalies by nuclides with $\tau_{1 / 2} \gtrsim$ $10^{6}$ years. The many peculiar isotopic anomalies in $\mathrm{Xe}$ are now not isolated but appear to be part of a large family of complex isotopic anomalies extending beyond $Z=60$. The complex Xe spectra in residual material in Allende and other carbonaceous chondrites by Anders et al. (1975), Takahashi et al. (1976), and Lewis, Srinivasan, and Anders (1975) have been interpreted as due to superheavy fission and not due to $r$-process addition. This view has been subject to some discussion because of the enrichment in both neutron-poor and neutron-rich isotopes in the strange $\mathrm{Xe}$ which these workers discovered. This matter has been studied extensively by the Chicago group and by Frick (1977) and Frick and Reynolds (1977). In light of the existence of anomalies over a wide spread in $Z$, it now seems more plausible to consider the $\mathrm{Xe}$ anomalies to be the result of a very complex mixture of processes which include $r$-process components and various implantation mechanisms rather than superheavy fission.

The ball game seems to be wide open. The most likely generic model which may explain the observations appears to be an onion-shell supernova explosion followed by injection into the solar nebula, as outlined by Cameron and Truran (1977) to account for the O and $\mathrm{Mg}$ data. Such a model can produce elements of high $Z$. A reliable astrophysical model must await the experimental determination of the yields of exotic nuclei in the region of the rare earths where chemical fractionation will not obscure the relative contributions.

We are grateful to $H$. Nagasawa for the as yet unique sample of EK1-4-1. M. T. M. thanks D. A. Papanastassiou for his generous advice and introduction to high-precision mass spectrometry. D. J. DePaolo provided timely assistance and gave helpful advice. We thank R. Ward for his interest and advice on $p$ 's and $q$ 's and $s$ and $r$. The excitement was communally shared with our calcined colleagues, D. A. Papanastassiou and Typhoon Lee. This work was supported by NSF grant PHY76-83685 and NASA grant NGL 05-002-188.

\section{REFERENCES}

Anders, E., Higuchi, H., Gros, J., Takahashi, H., and Morgan, J. W. 1975, Science, 190, 1262.

Burbidge, E. M., Burbidge, G. R., Fowler, W. A., and Hoyle, F. 1957, Rev. Mod. Phys., 29, 547 ( (B2 FH).

Cameron, A. G. W. 1973, Space Sci. Rev., 15, 121

Cameron, A. G. W., and Truran, J. W. 1977, Icarus, 30, 447.

Clayton, R. N., Grossman, L., and Mayeda, T. K. 1973, Science, 182,485 .

Clayton, R. N., and Mayeda, T. K. 1977, Geophys. Res. Letters, $4,295$.

DePaolo, D. J., and Wasserburg, G. J. 1976, Geophys. Res. Letters, 3, 249.

Eugster, O., Tera, F., and Wasserburg, G. J. 1969, J. Geophys. Res., 74, 3897 (ETW).

Frick, U. 1977, Proc. 8th Lunar Sci. Conf. (Oxford: Pergamon Press), in press.

Frick, U., and Reynolds, J. H. 1977, in Lunar Science VIII (Houston: Lunar Science Institute), p. 319.

Grossman, L. 1972, Geochim. Cosmochim. Acta, 36, 597.

Lee, T., Papanastassiou, D. A., and Wasserburg, G. J. 1977, $A$ p. J. (Letters), 211, L107.
- - 1978, Ap.J. (Letters), 220, this issue.

Lewis, R. S., Srinivasan, B., and Anders, E. 1975, Science, 190 1251

McCulloch, M. T., Papanastassiou, D. A., and Wasserburg, G. J. 1976, Meteoritics, 11, 331.

Podosek, F. A. 1970, Geochim. Cosmochim. Acta, 34, 341.

Reynolds, J. H. 1960, Phys. Rev. Letters, 4, 8.

Scheinin, N. B., Lugmair, G. W., and Marti, K. 1976, Meteoritics, $11,357$.

Schramm, D. N., and Wasserburg, G. J. 1970, Ap. J., 162, 57. Seeger, P. A., Fowler, W. A., and Clayton, D. D. 1965, Ap. J. Suppl., 11, 121.

Stroud, D. B. 1972, Ap. J. (Letters), 178, L93

Takahashi, H., Higuchi, H., Gros, J., Morgan, J. W., and Anders, E. 1976, Proc. Nat. Acad. Sci., 73, 4253.

Ward, R. A., Newman, M. J., and Clayton, D. D. 1976, Ap. J. Suppl., 31, 33.

Wasserburg, G. J., Lee, T., and Papanastassiou, D. A. 1977, Geophys. Res. Letters, 4, 299 (WLP).

Wasserburg, G. J., Papanastassiou, D. A., Nenow, E. V., and Bauman, C. A. 1969, Rev. Sci. Instr., 40, 288. 